\title{
Legg-Calvé-Perthes hastalığının klinik ve radyolojik değerlendirilmesi ve direkt radyografi temelli sınıflama sistemleri
}

\section{Clinical and radiological evaluation of Legg-Calvé-Perthes disease and direct radiography-based classification systems}

\author{
Hasan Hilmi Muratlı ${ }^{1}$, Hüsamettin Özdemir ${ }^{2}$ \\ 1Trakya Üniversitesi Tıp Fakültesi Ortopedi ve Travmatoloji Anabilim Dalı, Edirne \\ ${ }^{2}$ Sultan 1. Murat Devlet Hastanesi Ortopedi ve Travmatoloji Kliniği, Edirne
}

Bu gözden geçirme çalışmasında Legg-Calvé-Perthes hastalığının klinik ve radyolojik değerlendirme bulgularını özetlemek ve Legg-Calvé-Perthes hastalarını direkt radyografiler kullanarak değerlendiren sınıflandırma sistemlerini açıklamak amaçlanmıştır.

Anahtar sözcükler: Legg-Calvé-Perthes; sınıflandırma; radyoloji
In this review we aimed to summarize clinical and radiological evaluation criteria and to explain classification systems which use the X-ray evaluation of the patients with LeggCalvé-Perthes disease.

Key words: Legg-Calvé-Perthes; classification; radiology

\section{KLINIK BULGULAR}

Legg-Calvé-Perthes (LCP) hastalığı, femur başının idiyopatik osteonekrozudur. Hastalık, 1910 yılında birbirlerinden bağımsız olarak, Legg (Amerika Birleşik Devletleri), Calvé (Fransa) ve Perthes (Almanya) tarafından tanımlanmıştır ve Legg-Calvé-Perthes hastalığı olarak bilinir. Birçok çalışma ve teoriye rağmen etiyolojisi net olarak açıklanamamıştır. ${ }^{[1]}$ Beyaz ırk, obezite, asetabular retroversiyon, femur baş ve boynunda anormal venöz drenaj, beslenme, hiperaktivite, koagülopati, faktör $V$ Leiden mutasyonu, bilinen risk faktörleri arasındadır. Erkek çocuklarda kızlara oranla dört kat daha sık görülmekte ve \%10-15 oranında bilateral tutulum olmaktadır. ${ }^{[2]}$ Femur başında kan akımında azalma ile kendini gösteren, çoğunlukla 2-12 yaş aralığındaki çocuklarda görülen bir rahatsızlıktır. Ağrı, femur başının çökmesi ve nihai olarak osteoartrit ile sonuçlanabilecek bir klinik süreç izler. Septik artrit ve transient sinovit ile karışabilir. LCP'de hastalık, haftalar aylar gibi daha uzun zaman periyoduna yayılır.

Klinik tablo, ağrısız topallama ile başlayıp irritabl kalçaya kadar uzanabilir. Ağrı çoğunlukla kasık bölgesinde ve aktivite ile artıp istirahatle azalan karakterdedir;

fakat, hastalığın ilerleyen dönemlerinde sinirlerin etkilenmesine bağlı olarak, kalça önü ve çevresinde (siyatik sinir), uylukta (obturator sinir) ve diz çevresinde (femoral sinir) de görülebilir. Topallama, genellikle hem ağrıya hem de abduktor kas güçsüzlüğüne bağlı olarak oluşur. En sık belirti, genellikle aileler tarafından fark edilen ağrısız topallamadır. Bu nedenle, aksayan ya da diz çevresinde ağrısı olan çocuklarda Perthes hastalığı akılda tutulmalıdır. Fizik muayenede, erken dönemde kalça hareketlerinden iç rotasyon ve abduksiyon en sık etkilenir. Hareket kısıtlığının nedeni erken dönemlerde sinovit ve kas gerginliğine bağlı olmakla beraber, sonraki dönemlerde eklemin bozulmasına bağlıdır. ${ }^{[3,4]}$

\section{RADYOLOJiK BULGULAR VE EVRELENDIRME}

Direkt ön-arka ve kurbağa pozisyonunda çekilen grafiler, hastalığın tanı ve izleminde en önemli görüntüleme yöntemleridir. Karakteristik tipik değişiklikler, hastalığın başlamasından tipik olarak 3-6 ay sonra, direkt grafilerde görülmeye başlanır; effüzyon, nispeten kalınlaşmış kıkırdak, artmış mediyal eklem aralığı şeklinde görülebilir. Tutulan kalçada küçük bir ossifik çekirdek mevcuttur. ${ }^{[5]}$ Femur başında düzleşme, skleroz

- Illetişim adresi: Prof. Dr. Hasan Hilmi Muratlı, Merkez Mah. Selimiye Cad. Aktürk-Rapsodi Evleri, Melodi 4B, Daire: 5, Çekmeköy, İstanbul Tel: 0505 - 2007709 e-posta: hasanmuratli@yahoo.com

- Geliștarihi: 20 Șubat $2017 \quad$ Kabul tarihi: 20 Șubat 2017 


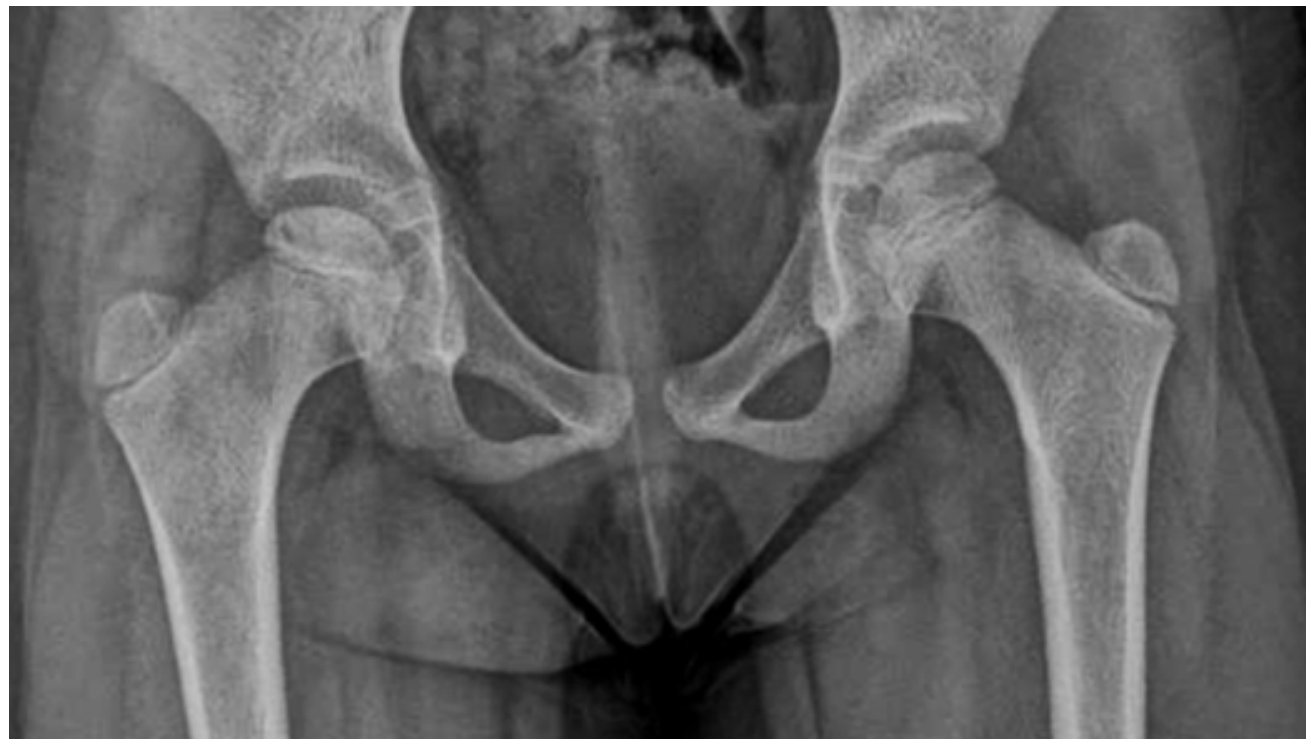

Şekil 1. Evre 1 (artmış yoğunluk veya başlangıç evresi).

ve hilal işareti bulguları grafilerde görülebilir. Perthes hastalığının tanısının konulmasında, izlenmesinde, erken ve geç dönem sonuçların değerlendirilmesinde, çeşitli sınıflamalar mevcuttur.

\section{Waldenström Radyolojik Evrelemesi}

Illk olarak 1938 yılında, radyolojik evreleme sistemine göre sınıflama yapılmıştır. ${ }^{[6]}$

Bulgular, hastalı̆̆ın patolojik seyrine göre gruplandırılmıştır. Genel olarak, başlangıç, fragmantasyon, reossifikasyon ve yeniden şekillenme olarak dört evrede incelenir. Bu sınıflama, hastalığın evresini gösterir fakat prognoz hakkında bilgi vermez. ${ }^{[7]}$

\section{Evre 1 (artmış yoğunluk veya başlangıç evresi)}

Erken dönemde, femur başında yoğunluk artar ve eklem aralığında artma görülür; geç dönemde ise olguların yaklaşık üçte birinde subkondral bölgede çizgisel kırık hattı oluşabilir. Waldenström işareti olarak bilinen bu durum, en iyi kurbağa pozisyonundaki yan grafilerde görülür. Metafizde radyolusen alanlar görülebilir. Bu evrede, patolojik olarak eklem kıkırdağı kaIınlaşmıştır ve femur başında nekroz vardır. Klinik olarak ağrı ve topallama görülür. Ortalama altı ay sürer (Şekil 1).

\section{Evre 2 (fragmantasyon evresi)}

Femur başında radyolusen alanlar belirgin hale gelmekle beraber, litik ve sklerotik alanlar görülür. Femur başı düzleşmeye ve genişlemeye başlar; yoğunluk artışı düzelir; asetabulum genellikle düzensizdir. Klinik olarak ağrı ve topallama daha şiddetli hale gelir; eklem hareket kısıtlığı görülebilir. Ortalama sekiz ay sürer (Şekil 2).

\section{Evre 3 (reossifikasyon ya da iyileşme evresi)}

Femur başında subkondral bölgede yeni kemik oluşumu görülür. Yeni kemikleşme, genellikle başın

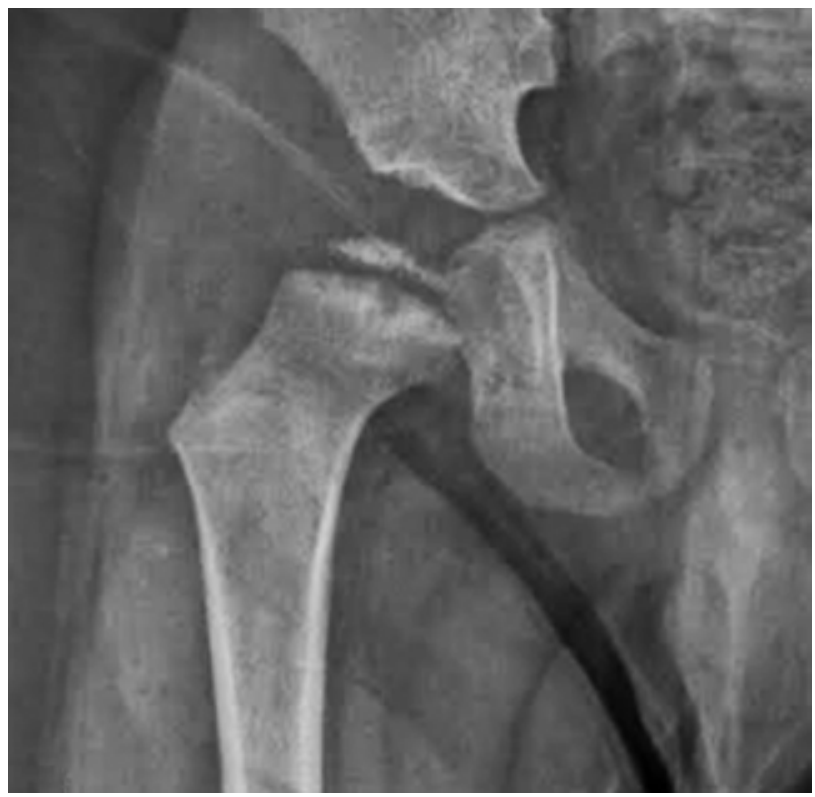

Şekil 2. Evre 2 (fragmantasyon evresi). 


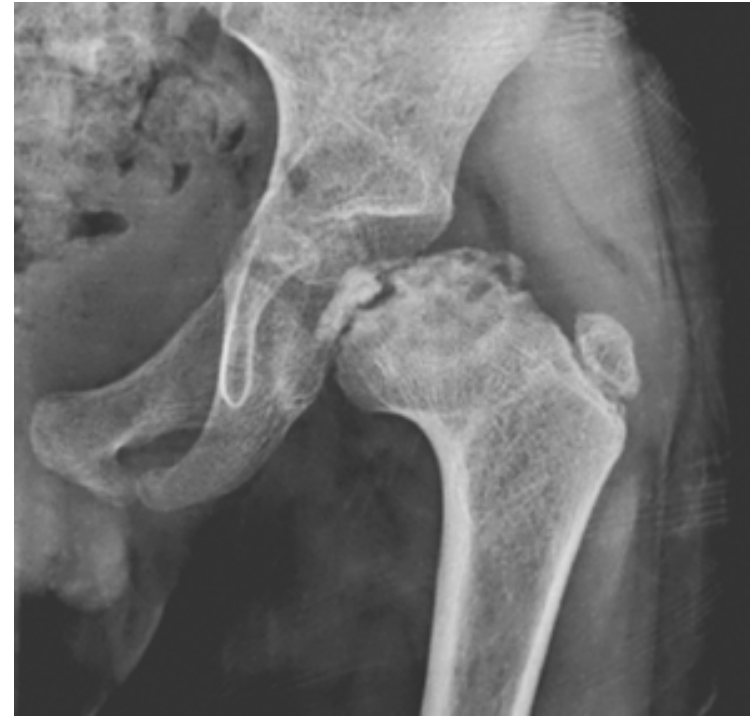

Şekil 3. Reossifikasyon ya da iyileşme evresi.

merkezinden başlayıp mediyal ve laterale doğru olur. Radyolusen görünüm ortadan kalkar; epifiz homojenleşir ve örülmüş kemik dokusu oluşur. Femur başı eski yuvarlaklığını kazanmaya başlar. Prognozu kötü olgularda femur başında yassılaşma artar. Prognozu iyi olgularda klinik olarak ağrı ve topallama düzelir, eklem hareket açıklı̆ı artmaya başlar. Ortalama 51 ay sürer (Şekil 3).

\section{Evre 4 (yeniden şekillenme)}

Femur başı yoğunluğunda farklı değişiklikler olmaz, tamamen kemikleşir; iskelet gelişimi bitene kadar süren bir evredir.

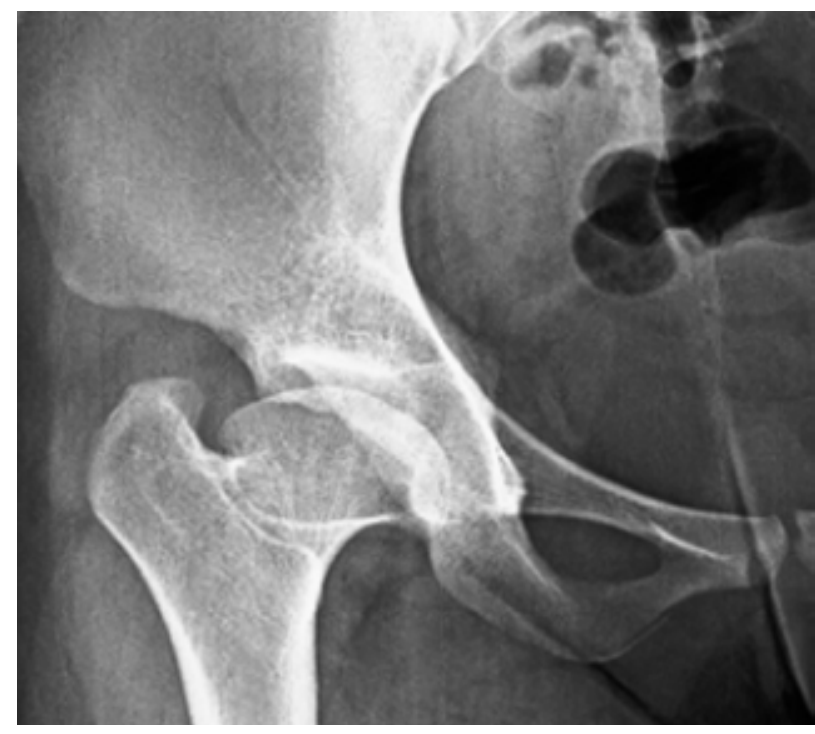

Şekil 4. Yeniden şekillenme.

Femur başının şekli tamamen normalden ileri derecede düz ve asferik olana kadar değişkenlik gösterebilir. (Şekil 4)

\section{Catterall Sınıflaması}

Perthes hastalığının femur başı epifız tutulum miktarına göre yapılan sınıflama şeklidir. Prognoz hakkında bilgi verir. Gruplar arası ayrım yapmak zordur; bu da gözlemciler arasında görüş farklılığı oluşmasına neden olmaktadır (Şekil 5).

Grup 1'de epifizin ön kısmında tutulum vardır, başta çökme ve metafizer reaksiyon gözlenmez.

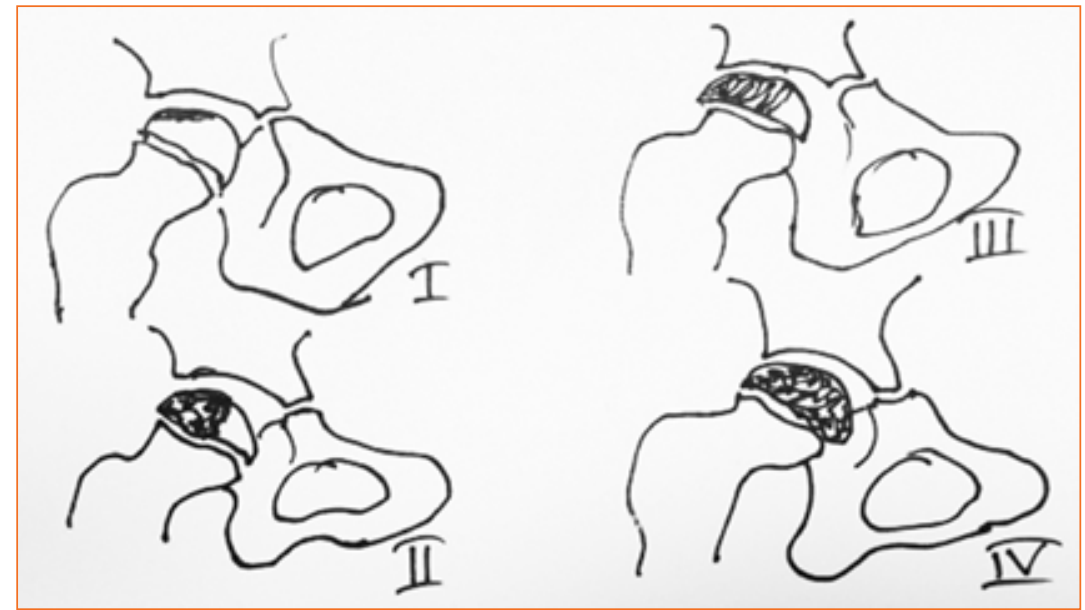

Şekil 5. Catterall sınıflaması. 


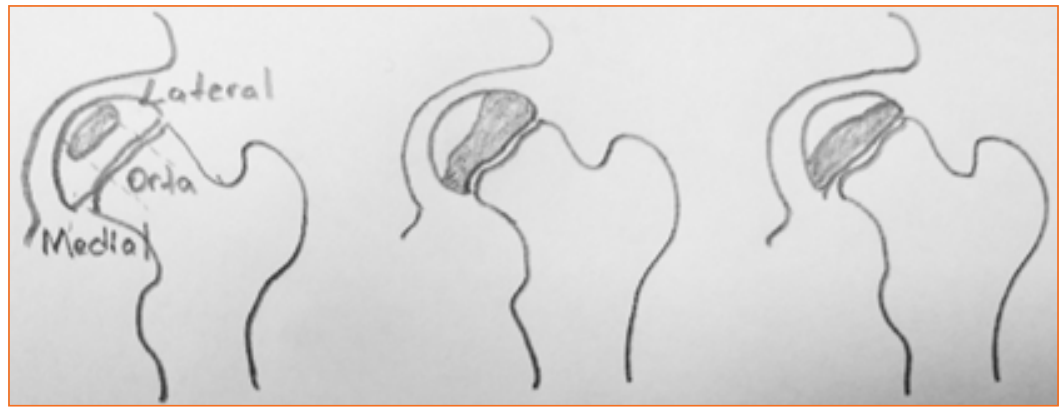

Şekil 6. Herring sınıflaması. (Lateral kolon; Orta kolon; Mediyal kolon).

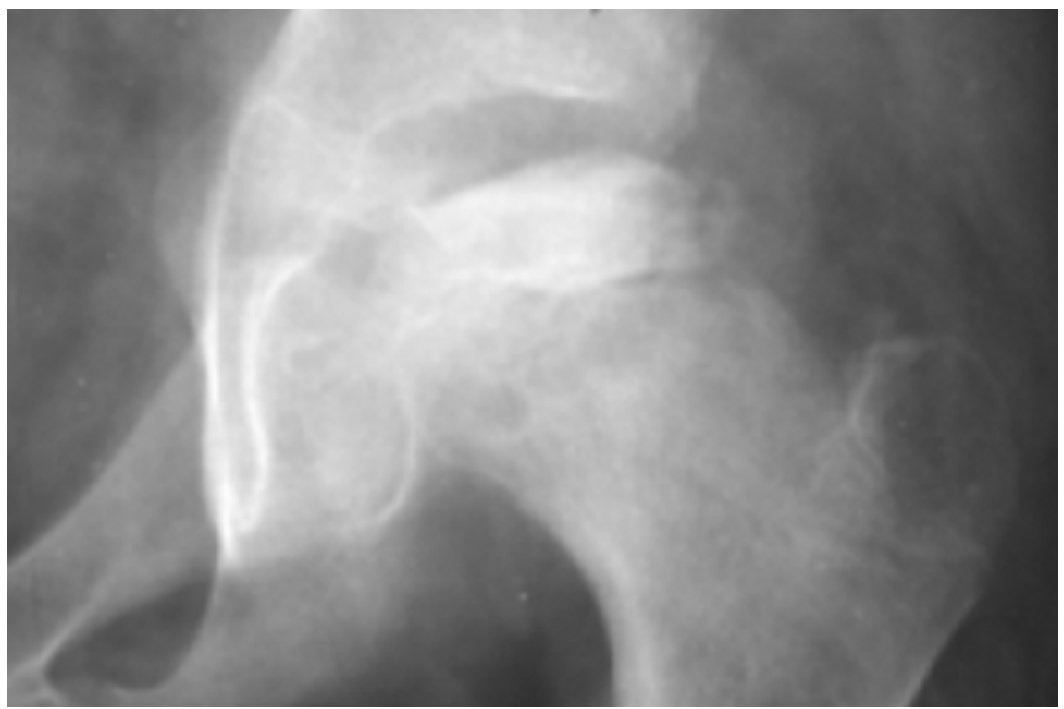

Şekil 7. Grup B/C.

Grup 2'de epifizin anterolateral \%50'lik bölümü etkilenmiştir; epifiz yüksekliği korunmuştur.

Grup 3'te başın \%75'i tutulmuştur. Ciddi metafizyel raksiyon vardır. Epifizin büyük kısmı sekestre olmuştur.

Grup 4'te epifizin tamamı tutulmuştur; tümüyle çökme ve sekestr oluşmuş̧tur. ${ }^{[8]}$

\section{Salter-Thompson Sinıflaması}

1984'te tanımlanmış olup, subkondral kırık varlığına ve epifiz tutulumuna göre iki grupta incelenmiştir. Grup A'da epifizin yarısından az bölümü tutulmuş ve epifiz dış kısmı sağlam kalmıştır; iyi prognozla ilişkilendirilmiştir. Catterall Grup 1 ve 2'ye denk düşer.

Grup B'de ise epifizin yarısından fazlası tutulmuş olup dış kısmı da sağlam değildir ve kötü prognozla ilişkilendirilmiştir. Catterall Grup 3 ve 4'e denk düşer. ${ }^{[9]}$

\section{Herring (Lateral Kolon) Sınıflaması}

1992 yılında tanımlanmış olup, femur başını önarka grafide üç eşit kısma ayırmış ve femur başının \%15-30'luk dış kısmındaki radyolojik değişiklikleri dikkate alarak, lateral kolon yüksekliğindeki korunmaya bağlı üç grupta sınıflamıştır. Sınıflama, erken fragmantasyon evresinde ve hastalık belirtileri başladıktan en az altı ay sonra yapılabilmektedir. (Şekil 6)

Grup A'da, erken fragmantasyon evresinde dış kolonda çok az yoğunluk değişikliği vardır ve çökme yoktur. Grup B'de dış kolon yükseklik kaybı \%50'den az, Grup C'de ise çökme \%50'den fazladır.

Grup B/C sınıflamaya sonradan eklenmiş olup B ile C grupları arasındaki sınırı oluşturur. Grup A en iyi prognoza sahipken, hastalığın başlangıcındaki dokuz yaşından küçük çocuklarda Grup B'de sonuçlar iyi olmasına rağmen, dokuz yaşın üstündeki çocuklarda sonuçlar kötü olarak belirtilmiştir. Grup $C$ ise en kötü prognoza sahiptir. Günlük klinik uygulamada bu sınıflama kullanılmaktadır (Şekil 7). ${ }^{[10]}$ 


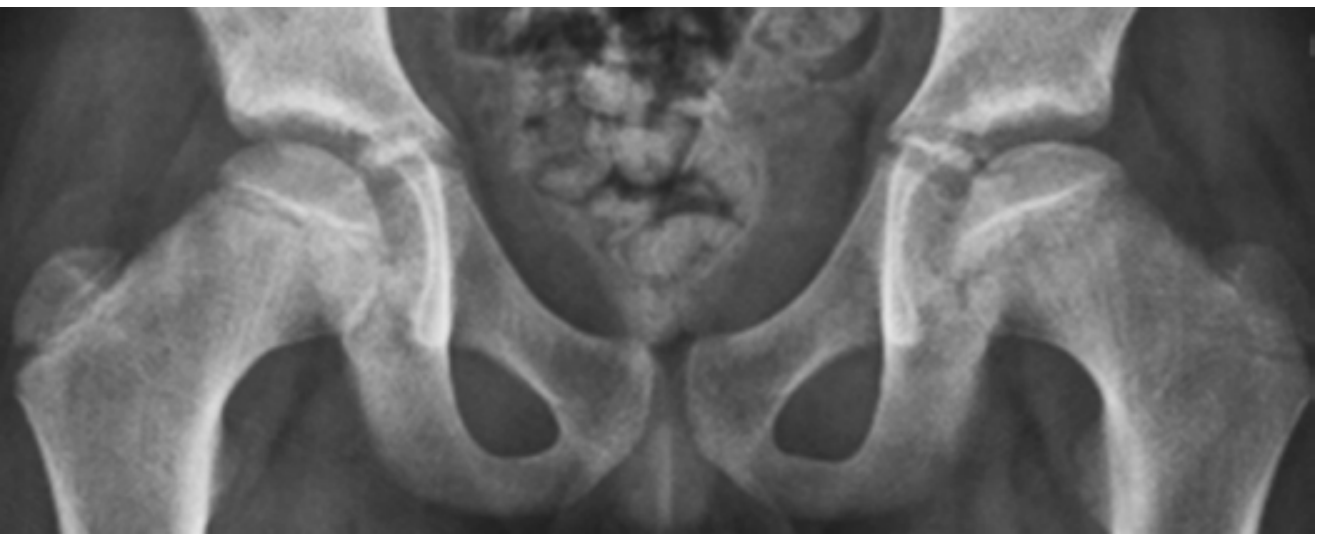

Şekil 8. Stulberg sınıflaması, Grup 1.

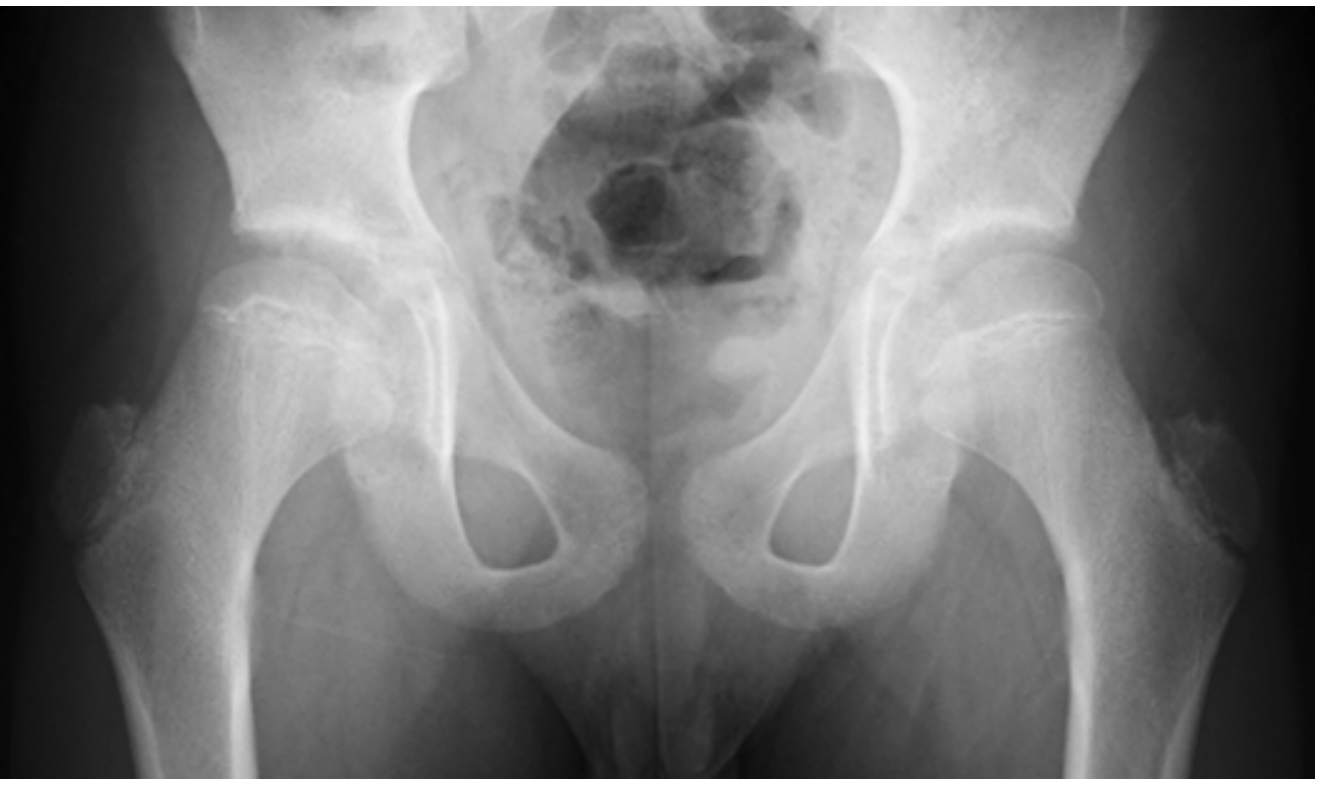

Şekil 9. Stulberg sınıflaması, Grup 2.

\section{UZUN DÖNEM SONUÇLARININ DEĞERLENDIRILMESi}

\section{Stulberg Sınıflaması}

Sonuçların değerlendirilmesi amacıyla tanımlanmış bir sınıflamadır. Stulberg ve arkadaşları, bu sınıflamayı ilk olarak 1981 yılında tanımlamışlardır. Bu sistemde, femur başı asetabulumdaki radyolojik değişiklikler (femur başının sferisitesi, femur boynunun uzunluğu, asetabulumun pozisyonu, coxa magna'nın varlığı) ön-arka ve yan grafilerde incelenmiş ve beş alt grupta değerlendirilmiştir.

Grup 1'de kalça eklemi bütünüyle normaldir (Şekil 8).

Grup 2'de femur başı yuvarlaktır; normalden büyük bir baş, kısa femoral boyun ve yapısı bozulmuş, sığ asetabulum mevcuttur (Şekil 9).
Grup 3'te yuvarlak olmayan, oval, mantar veya şemsiye şeklinde femoral baş, kısa femur boynu ve sığ asetabulum mevcuttur (Şekil 10).

Grup 4'te femur başı ve asetabulum düzleşmiş durumda olup, kalça fleksiyon ve ekstansiyonu mevcutken rotasyon kaybı oluşmuş durumdadır (Şekil 11).

Grup 5'te femur başı düzdür, fakat femur boynu ve asetabulumda değişiklik yoktur (Şekil 12). ${ }^{[11]}$

Stullberg, femur başı, asetabulumun eklem yüzleri ile uyumu ve dejeneratif koksartroz ile ilişkili olduğunu belirtmiş ve üç tip uyumdan söz etmiştir. Bu sınıflamanın güvenilirliği yüksektir ve sonuçların değerlendirilmesinde kullanılmaktadır.

Grup 1 ve Grup 2: Sferik uyumlu. Koksartroz gelişimi beklenmez. 


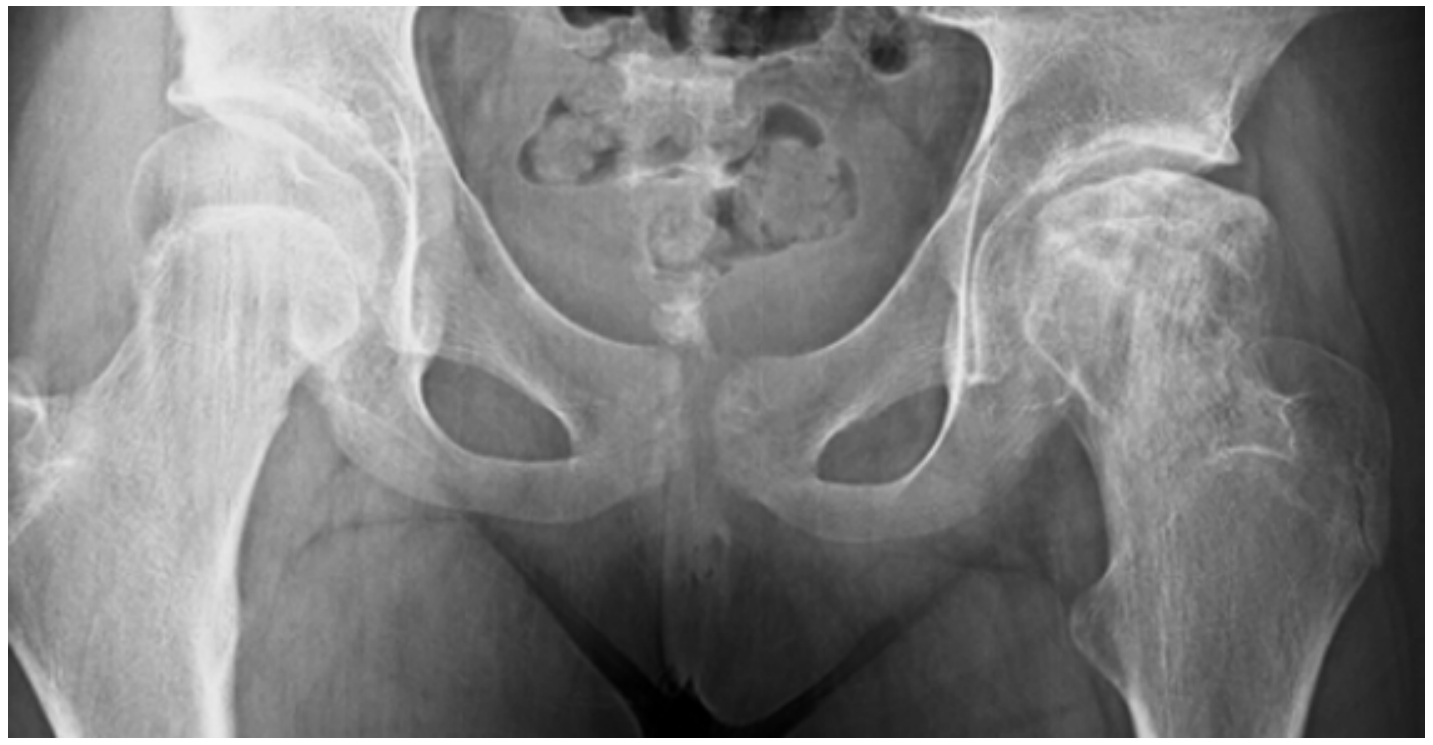

Şekil 10. Stulberg sınıflaması, Grup 3.

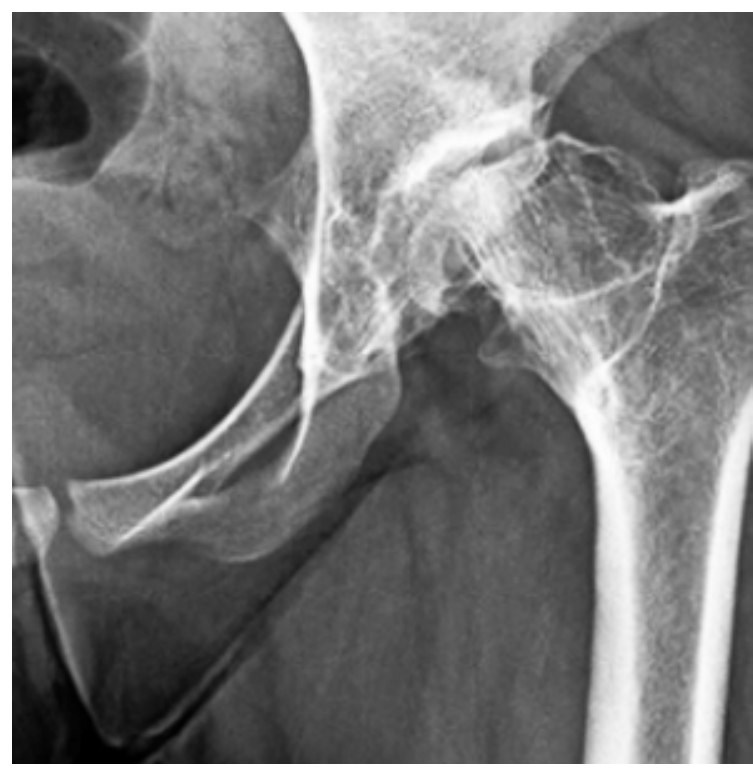

Şekil 11. Stulberg sınıflaması, Grup 4.

Grup 3 ve Grup 4: Asferik uyumlu. Hafif-orta koksartroz gelişimi beklenir.

Grup 5: Asferik-uyumsuz. Elli yaş altında ciddi koksartroz gelişimi beklenir.

\section{Mose Sınıflaması}

Sonuçların değerlendirilmesi amaçlı, $2 \mathrm{~mm}$ aralıklı artan halkalar içeren bir şablon kullanılır. Ön-arka ve yan grafilerde şablon ile başın küreselliği ölçülür. Bu

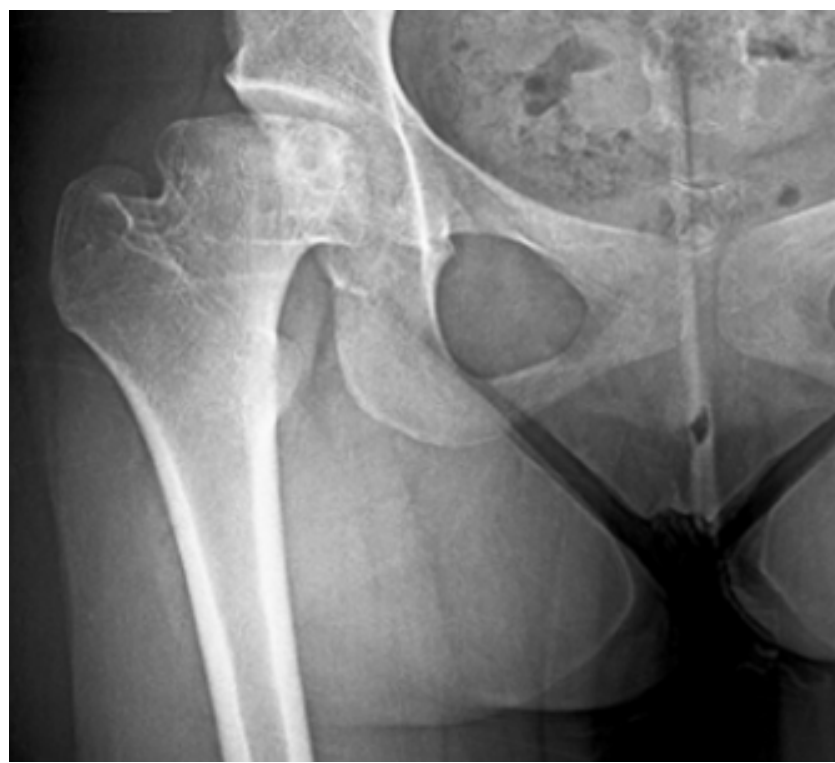

Şekil 12. Stulberg sınıflaması, Grup 5.

halkalara göre baş, küresel, düzleşmiş ve düzensiz olarak üç gruba ayrılır. Dejeneratif eklem hastalığı riskinin düzensiz başlarda yüksek olacağı ve bu grupta prognozun iyi olmayacağı gösterilmiştir. ${ }^{[12]}$

1- Çember şablondan $1 \mathrm{~mm}$ 'den daha az sapma gösteriyorsa prognoz iyidir.

2- Çember şablondan 2 mm'ye kadar sapma gösteriyorsa prognoz vasattır.

3- Çember şablondan 2 mm'den fazla sapma gösteriyorsa prognoz kötüdür. ${ }^{[13]}$ 


\section{KAYNAKLAR}

1. Krul M, van der Wouden JC, Schellevis FG, van Suijlekom-Smit LW, Koes BW. Acute nontraumatic hip pathology in children: incidence and presentation in the family practice. Fam Pract 2010;27(2):166-70. Crossref

2. Perry DC, Machin DM, Pope D, Bruce CE, Dangerfield P, Platt MJ, Hall AJ. Racial and geographic factors in the incidence of Legg-Calvé-Perthes' disease: a systematic review. Am J Epidemiol 2012;175(3):159-66. Crossref

3. Herring JA. Tacdjian's pediatric orthopaedics 4th ed. Philadelphia: Saunders Elsevier; 2008. p.771-837.

4. Weinstein SL. Legg-Calvé-Perthes syndrome. In: Morrissey RT, Weinstein SL, editors. Lovell and Winter's Pediatric Orthopaedics, 5th ed. Philadelphia: Lippincott Williams Wilkins; 2001. p.957-98.

5. Cho TJ, Choi IH, Chung CY, Yoo WJ, Lee KS. The bicompartmental acetabulum in Perthes' disease: 3D-CT and MRI study. J Bone Joint Surg Br 2005;87(8):1127-33.

6. Waldenström $\mathrm{H}$. The classic. The first stages of coxa plana by Henning Waldenström 1938. Clin Orthop Relat Res 1984;(191):4-7.
7. Wingstrand $H$. Significance of synovitis in Legg-Calvé-Perthes disease. J Pediatr Orthop B 1999;8(3):156-60.

8. Catterall A. The natural history of Perthes' disease. J Bone Joint Surg Br 1971, 53(1):37-53.

9. Salter RB, Thompson GH. Legg-Calvé-Perthes disease. The prognostic significance of the subchondral fracture and a two-group classification of the femoral head involvement. J Bone Joint Surg Am 1984;66(4):479-89.

10. Herring JA, Neustadt JB, Williams JJ, Early JS, Browne RH. The lateral pillar classification of Legg-Calvé-Perthes disease. J Pediatr Orthop 1992;12(2):143-50.

11. Stulberg SD, Cooperman DR, Wallensten R. The natural history of Legg-Calvé-Perthes disease. J Bone Joint Surg Am 1981;63(7):1095-108.

12. Mose K. Methods of measuringin Legg-Calvé-Perthes disease with special regard to the prognosis. Clin Orthop Relat Res 1980;(150):103-9.

13. Erdost UŞ. Hiperbarik oksijen tedavisinin Legg-Calvé-Perthes hastalığının tedavisindeki etkinliği (Tez) İstanbul: TC Sağlık Bakanlığı Baltalimanı Metin Sabancı Kemik Hastalıkları Eğitim ve Araştırma Hastanesi, 1. Ortopedi ve Travmatoloji Kliniği; 2008. 